\title{
Effect of rolling temperatures on mechanical and fracture behavior of AA 3003 alloy and pure $\mathrm{Cu}$
}

\author{
Kandarp Changela' ${ }^{1}$ - H. B. Naik ${ }^{2} \cdot$ K. P. Desai ${ }^{2} \cdot$ H. K. Raval ${ }^{2}$
}

Received: 30 January 2020 / Accepted: 13 May 2020 / Published online: 21 May 2020

(c) Springer Nature Switzerland AG 2020

\begin{abstract}
Ultrafine-grained materials have an enormous scope of structural and functional applications owing to their higher mechanical properties compared to that of coarse-grained materials. The influence of room temperature and cryogenic temperature rolling of AA 3003 alloy and pure $\mathrm{Cu}$ on its mechanical properties and fracture behavior has been investigated in the present study. Both the materials are rolled to a thickness of $2 \mathrm{~mm}$ and $1 \mathrm{~mm}$ with a true plastic strain of 0.40 and 1.09, respectively. The deformed samples are characterized by tensile test, hardness test, and X-ray diffraction analysis. It has been observed that tensile strength and hardness of cryorolled (CYR) samples are higher than cold rolled (CR) samples and it is due to the fact that rolling at an extremely low temperature $\left(-196^{\circ} \mathrm{C}\right)$ suppresses the dynamic recovery and hence mobility of dislocations becomes difficult as a result dislocation density increases. In CYR, low stacking fault energy material $(\mathrm{Cu})$ has higher tendency to increase strength and work hardened compared to higher stacking fault energy materials (AA 3003) without much loss of ductility. SEM pictorial view of fractography revealed that CYR samples have mix mode of failure compared to CR samples. The dimple size is gradually decreased with increasing plastic strain and that is due to severe strain hardening and grain refinement.
\end{abstract}

Keywords Cryorolling $\cdot$ Ultrafine-grain · Dislocation density $\cdot$ Stacking fault energy

\section{Introduction}

Ultrafine-grained (UFG) materials with grain sizes between $100 \mathrm{~nm}<\mathrm{d}<1 \mu \mathrm{m}$ have been receiving significant attention towards structural and functional applications due to their improved mechanical properties such as higher strength and hardness as compared to that of coarsegrained (CG) materials. By reducing the grain size down to the nanometer or partly nanometer regime, UFG structured materials provide an excellent opportunity to study fundamental structure-property relationships and deformation mechanisms in polycrystalline materials [1]. The effect of grain size on the yield strength of polycrystalline materials at low temperatures (typically up to $0.5 \mathrm{Tm}$, where Tm is melting temperature of materials) is given by Hall [2] and greatly extended by Petch [3].

$\sigma_{y}=\sigma_{0}+K d^{-1}$

where $\sigma_{y}$ is the yield strength, $\sigma_{o}$ is the lattice friction, $\mathrm{K}$ is the Hall-petch constant and $d$ is the grain size.

It is clear from Eq. 1 that a reduction in grain size leads to an increase in the yield strength. Smaller grain size results in a large area of grain boundary network and hence the mobility of dislocations becomes more difficult. This leads to an increase in stress required for plastic deformation. In addition to that, reducing grain size up to the nanometer scale can also alter the physical, chemical, and mechanical behavior of materials [4].

Kandarp Changela, kandarp.changela06@gmail.com | 'Department of Mechanical Engineering, Indian Institute of Technology Delhi, New Delhi 110016, India. ${ }^{2}$ Department of Mechanical Engineering, S.V. National Institute of Technology Surat, Surat, Gujarat 395007 , India. 
Two fundamental approaches have been developed to synthesize UFG materials [5]. These are "bottom-up" approach and "top-down" approach. In "bottom-up" approach, bulk nanostructured materials are made from individual atoms or nanoscale building blocks such as nanoparticles. Inert gas condensation [6], high-energy ball milling [7], chemical vapor deposition [8], and cryomilling with hot isostatic pressing [9] are common examples of a bottom-up approach. However, in practice, there are fundamental disadvantages with these techniques because the samples are very small, they invariably contain some degree of residual porosity, and they are primarily suitable for use in micro-devices, i.e., electronic devices. The second approach is a "top-down" approach, in which existing coarse-grained materials are refined into UFG structured materials most commonly through severe plastic deformation. This approach eliminates the limitation of "bottomup" approach and can be implement to a wide range of metals and alloys. Valiev et al. [10,11] used this approach successfully in the early 1990 s to produce bulk materials with homogeneous and equiaxed UFG microstructures [12].

Many SPD processes have been developed to fabricate UFG materials including equal channel angular pressing (ECAP), high pressure torsion (HPT), accumulative roll bonding (ARB), friction stir processing (FSP), asymmetric rolling (AR), cryrolling (CYR), and constrained groove pressing (CGP). Some of these techniques, such as ECAP, HPT, and ARB [13-15], are already well established and capable of producing UFG bulk materials for structural applications. However, these techniques have some fundamental limitations for industrial applications such as taking large load during processing and high cost [16]. These SPD techniques are not suitable for producing sheet materials with UFG structure [17]. Moreover, the level of grain refinement becomes inefficient at higher strain which is a serious concern during SPD processes [18]. It has been reported that the rate of grain refinement can be further enhanced by changing the deformation temperatures [19].

Cryorolling (CYR) is one of the methods to solve the above problems. It constitutes an interesting and potential thermo-mechanical processing route to produce UFG sheets of pure metals and alloys, which causes significant microstructural refinement and enhances strength [19]. It requires less plastic strain to produce sub-microcrystalline structural features in the materials when compared to other SPD processes [20]. Cryorolled sheets possess submicron crystallite structures with low angle grain boundaries in its highest possible deformed condition [21-23]. However, the ductility of cryorolled samples is relatively low. In recent times, researchers are focus on increasing the ductility of ultrafine-grained materials without much loss of strength. It is very difficult to get ultrafine-grain structured with optimized strength and ductility for high stacking fault energy materials i.e. Al and Al alloys (SFE $160-200 \mathrm{~J} \mathrm{~m}^{-2}$ ) using cryorolling SPD process. A significant loss in elongation is reported [24] of cryorolled pure Al. Low tensile ductility of UFG materials attributed to low work hardening rate due to the inability to accumulate the dislocations inside the grains [25]. It is well established that stacking fault energy (SFE) is an intrinsic material parameter, which greatly influence on mechanical properties and microstructure during SPD process. In recent times, researchers are focus on increasing ductility of ultrafinegrained materials without much loss of strength by tailoring stacking fault energy $[26,27]$. An et al. [28] studied the influence of SFE on the mechanical properties of $\mathrm{Cu}$ and $\mathrm{CU}-\mathrm{Al}$ alloys (SEF 70-78 $\mathrm{J} \mathrm{m}^{-2}$ ). The optimum combination of strength and elongation could be achieved in the $\mathrm{Cu}-\mathrm{Al}$ alloys attributed to the development of twins and stacking faults during the tensile test at room temperature. Sarma et al. [29] found the optimum SFE to get UFG materials through cryorolling process. Tian et al. [30] achieved the superior strength and ductility of low SFE Cu-Al alloys by simple cold rolling and annealing which is due to an increase in the fraction of twin boundaries by annealing at $400{ }^{\circ} \mathrm{C}$ for $10 \mathrm{~s}$.

The objective of the present work is to compare the mechanical properties of two different classes of FCC materials (in terms of stacking fault energy), AA 3003 and pure $\mathrm{Cu}$, processed through cold rolling and cryorolling. It is important to understand the deformation behavior of these two materials by considering stacking fault energy. Moreover, authors are trying to fill the lacunae of the existing research in the UFG domain by providing possible explanations. In the present work, AA 3003 alloy and pure $\mathrm{Cu}$ are selected as model materials for CYR and CR, and study the effect of plastic strain and rolling temperature on mechanical properties and fracture behavior.

\section{Experimental procedure}

AA 3003 (AA-3) and pure $\mathrm{Cu}(\mathrm{Cu})$ have been received in the form of sheets and samples with size of $210 \mathrm{~mm} \times 40 \mathrm{~mm} \times 3 \mathrm{~mm}$ were cut. The chemical composition of AA 3003 analyzed by spectroscopy (ASTM E 12512011) is shown in Table 1.

The materials were subjected to rolling at room temperature and cryogenic temperature to achieve 30\% and $70 \%$ thickness reduction. Several investigators [31, 32] have well established that $70 \%$ thickness reduction is sufficient in cryorolling to produce ultrafine-grained materials. Cold rolling and cryorolling were carried out on a two-high rolling mill with roll diameter of $135 \mathrm{~mm}$ at a rolling speed $10 \mathrm{rpm}$. Cryorolling experiment was 
Table 1 Chemical composition (wt\%) of AA 3003 alloy

\begin{tabular}{llllllllll}
\hline Al & $\mathrm{Cu}$ & $\mathrm{Mg}$ & $\mathrm{Si}$ & $\mathrm{Fe}$ & $\mathrm{Ni}$ & $\mathrm{Mn}$ & $\mathrm{Zn}$ & $\mathrm{Ti}$ & $\mathrm{Cr}$ \\
\hline Balance & 0.157 & 0.150 & 0.30 & 0.66 & 0.012 & 0.219 & 0.229 & 0.014 & 0.024 \\
\hline
\end{tabular}

performed by immersing the sample in liquid nitrogen $\left(\mathrm{LN}_{2}\right)$ bath for $10 \mathrm{~min}$ and immediately rolled the sample between two rollers. For every successive pass, the material was dipped for sufficient time to ensure liquid nitrogen temperature. It is imperative to maintain uniform cryogenic temperature throughout the volume of samples. A small degree of reduction per pass, about $4-5 \%$ was used in order to minimize the temperature rise during rolling and to achieve uniform distribution of strain.

The standard tensile properties (strength and ductility) of cryorolled and cold rolled samples were determined by uniaxial tensile tests as per ASTM standard E8M on TUE-CN 1000 screw-driven machine with an initial strain rate of $10^{-3} \mathrm{~s}^{-1}$. The yield strength was determined using $0.2 \%$ offset method. Assuming Hollomon power law, $\sigma=k \varepsilon^{n}$ where $n$ is strain hardening exponent and $k$ is strength coefficient, true stress $(\sigma)$-true strain $(\varepsilon)$ curves were plotted from the engineering stress-strain data. The hardness was measured on the samples using Vickers hardness tester to investigate the effect of accumulated plastic strain in cryorolled and cold rolled sheets. Hardness was measured parallel to length direction (rolling direction) of the sample by applying a load of $10 \mathrm{~kg}$ for $15 \mathrm{~s}$. An average of five measurements were taken to ensure the repeatability of each specimen.

$X$-ray diffraction (XRD) analysis was performed using $\mathrm{Cu} \mathrm{Ka}$ radiation $(0.154 \mathrm{~nm})$. Peak broadening were observed of AA-3003 and pure $\mathrm{Cu}$ for $70 \%$ thickness reduction in cryorolled condition (CYR-70) and assuming that changes in peak broadening is due to lattice strain, crystallite size and dislocation density parameters. Among various methods, Williamson-Hall method [33] is extensively used to evaluate the above parameters for UFG materials. Recently, this technique is used for cryorolled AA 5083 alloy [34]. For the present study, following Williamson-Hall equation is used

$B \cos \theta=2 \varepsilon \sin \theta+\frac{K \lambda}{D}$

where $B$ is the peak broadening, $\theta$ is the Bragg angle, $\varepsilon$ is the lattice strain, $K$ is the Scherrer constant (0.94), $\lambda$ is the wavelength of $X$-ray used $(1.54 \AA)$, and $D$ is the crystallite size. The intercept and slope of the plot of $B \cos \theta$ against $2 \sin \theta$ gives the average crystallite size (D) and lattice strain $(\varepsilon)$, respectively. Dislocation density $(\rho)$ after cryorolling and cold rolling were evaluated using the following equation. $\rho=\sqrt{\frac{3 \times K \times \varepsilon^{2}}{D^{2} \times b^{2}}}$

where $b$ is the Burgers vector.

The fractography of the cold rolled and cryorolled tensile specimens with their fracture surfaces were characterized by using scanning electron microscope (SEM-S3400N) with magnification ranging from $20 \times$ to approximately $30,000 \times$, spatial resolution of $50-100 \mathrm{~nm}$. For SEM study, small specimen was extracted from the tensile failure sample.

\section{Results and discussion}

\subsection{Time required of sample to reach $\mathrm{LN}_{2}$ temperature before cryorolling}

The important observation made in cryorolling process that the sample being rolled should remain in cryo condition (at a temperature between $-196^{\circ} \mathrm{C}$ and $-130^{\circ} \mathrm{C}$ ) during the rolling process. Because of the time gap between the sample removed from liquid nitrogen bath and rolling the specimen, the temperature will increase when exposed to ambient condition. In the present experiment, the time taken for taking out the samples from $\mathrm{LN}_{2}$ bath and rolling was observed to be $5 \mathrm{sec}$ and dipping the sample back in $\mathrm{LN}_{2}$ was observed to be less than $40-50 \mathrm{sec}$ during each pass in order to preclude the temperature rise of the samples.

Proper dipping time of the samples in liquid nitrogen was found to be 10 min and it was used subsequently during cryorolling. Figure 1 shows the effect of heat transfer coefficient on time required to reach $\mathrm{LN}_{2}$ temperature for AA-3 and $\mathrm{Cu}$ ( $3 \mathrm{~mm}$ thickness) samples. The heat transfer coefficient of these materials at $\mathrm{LN}_{2}$ temperature was observed in the order of $1000 \mathrm{~W} / \mathrm{m}^{2}{ }^{\circ} \mathrm{K}$. The theoretical time at different heat transfer coefficient was calculated as per Heisler chart from standard heat transfer data book. The lumped capacitance method was used to determine the variation of temperatures with time by neglecting the thermal gradient within the solid body. The following Eq. (4) was used to determine the time required for the solid to reach liquid nitrogen temperature.

$\frac{\theta}{\theta_{i}}=\frac{T-T_{\infty}}{T_{i}-T_{\infty}}=\exp \left[\left(-\frac{h A_{s}}{\rho V_{c}}\right) t\right]$ 


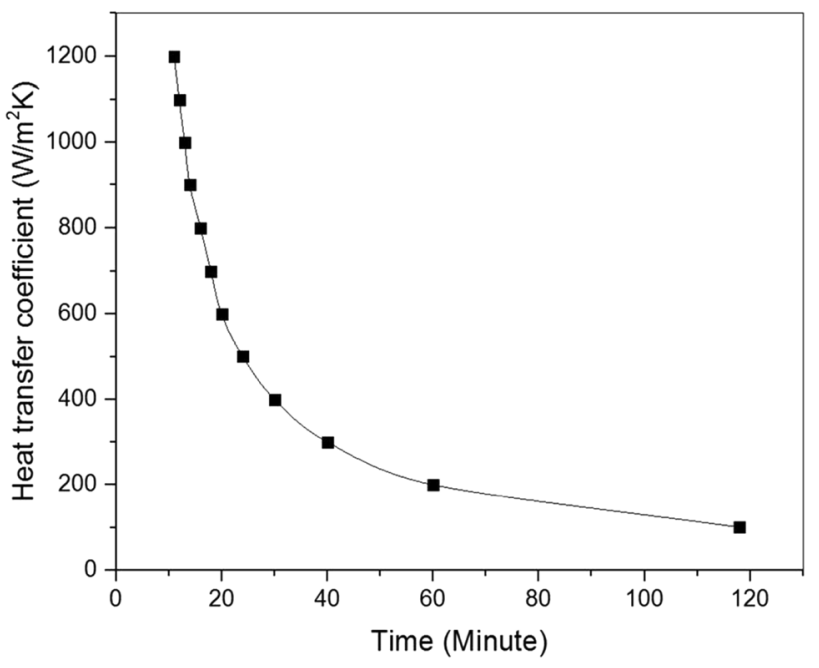

Fig. 1 Variation of heat transfer coefficient as a function of time

where $\mathrm{T}$ is the required temperature $\left({ }^{\circ} \mathrm{K}\right), T_{\infty}$ is the fluid (liquid nitrogen) temperature $\left({ }^{\circ} \mathrm{K}\right), T_{i}$ is the initial temperature $\left({ }^{\circ} \mathrm{K}\right), \mathrm{h}$ is the heat transfer coefficient in $\mathrm{W} / \mathrm{m}^{2}{ }^{\circ} \mathrm{K}, A_{s}$ is the surface area, $\rho$ is the density of a body, $V_{c}$ is the volume of a body, $t$ is the time required to reach temperature T. It was concluded from Eq. 4 that the time required in both the materials to reach $\mathrm{LN}_{2}$ temperature prior to cryorolling was around $10 \mathrm{~min}$. The mechanical properties of samples were presumably constant even for dipping the samples for more than $10 \mathrm{~min}$. To the authors' knowledge, the analysis for time requirement prior to cryorolling has not been reported earlier.

\subsection{Hardness properties}

The hardness values of cold rolled and cryorolled AA-3 and $\mathrm{Cu}$ alloys as a function of thickness reductions are shown in Fig. 2. The hardness in CYR AA-3 samples is considerably higher than in CR samples (nearly $23 \%$ increased for $30 \%$ and $70 \%$ thickness reduction). Nearly $30 \%$ hardness increased in CYR Cu for $30 \%$ and $70 \%$ thickness reduction than in $\mathrm{CR} \mathrm{Cu}$. The enhancement of hardness in the CYR materials is directly related to the suppression of dynamic recovery resulting to higher dislocation density and grain refinement. Because of twinning plays a significant role in grain refinement, the rate of increasing the hardness in $\mathrm{Cu}$ is higher than in AA-3 alloy.

\subsection{Tensile properties}

The dog bone tensile specimens with sub-size specifications (gauge length $25 \mathrm{~mm}$ ) are machined parallel to the rolling direction as per ASTM standard E8M-09. Figure 3a, $b$ shows the true stress-strain diagram of AA 3003 alloy

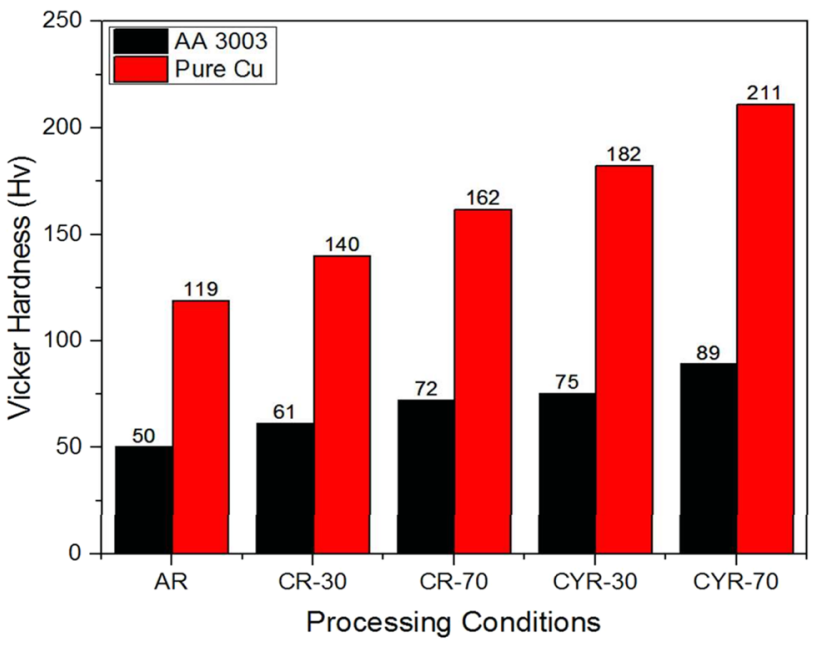

Fig. 2 Vicker hardness of AA 3003 alloy and pure Cu for different processing conditions

and pure $\mathrm{Cu}$ for cold and cryorolled samples at different thickness reduction. The respective tensile properties are summarized in Table 2.

It is clearly observed from Fig. 3 and Table 2 that the strength in cryorolled specimen is comparatively higher than in cold rolled specimen. The higher strength in cryorolled materials mainly due to higher work hardening effect and increased dislocation density during plastic deformation. The yield strength (YS) and ultimate tensile strength (UTS) in AA-3 alloy for CYR-70 condition are $190 \mathrm{Mpa}$ and $213 \mathrm{MPa}$, respectively which is increased from $168 \mathrm{Mpa}$ and $192 \mathrm{MPa}$, respectively for CR-70 condition (nearly 13\% YS increased and 10\% UTS increased). The corresponding YS and UTS in CYR-70 Cu have also been increased to $520 \mathrm{Mpa}$ and $702 \mathrm{MPa}$ respectively, compared to CR-70 specimens (439 Mpa and $482 \mathrm{Mpa}$, respectively) and it is expected to further increase with deformation. YS and UTS in CYR Cu are increased nearly $18 \%$ and $45 \%$ from CR Cu. However, as shown in Table 2, it could be noted that the elongation of CYR samples is similar or relatively lower than CR samples for both the materials and it is caused by low work hardening rate. The necking occurs immediately after the stress reaches to the maximum value in $\mathrm{Cu}$ while, post uniform elongation in AA-3 is higher than $\mathrm{Cu}$. It is important to note that, slightly large elongation occurs after the onset of necking in AA-3 alloy than $\mathrm{Cu}$ is due to the presence of continuous strain hardening behavior as shown in Fig. 3. The difference in elongation between two materials for all processing conditions is very small, but the significant difference has been found in strength. Hence, it can be conclude that $\mathrm{Cu}$ has a higher ability to improve the strength and ductility simultaneously than AA-3.

Dislocation motion, interaction, and multiplication are dynamic characteristics of materials to occur plastic 

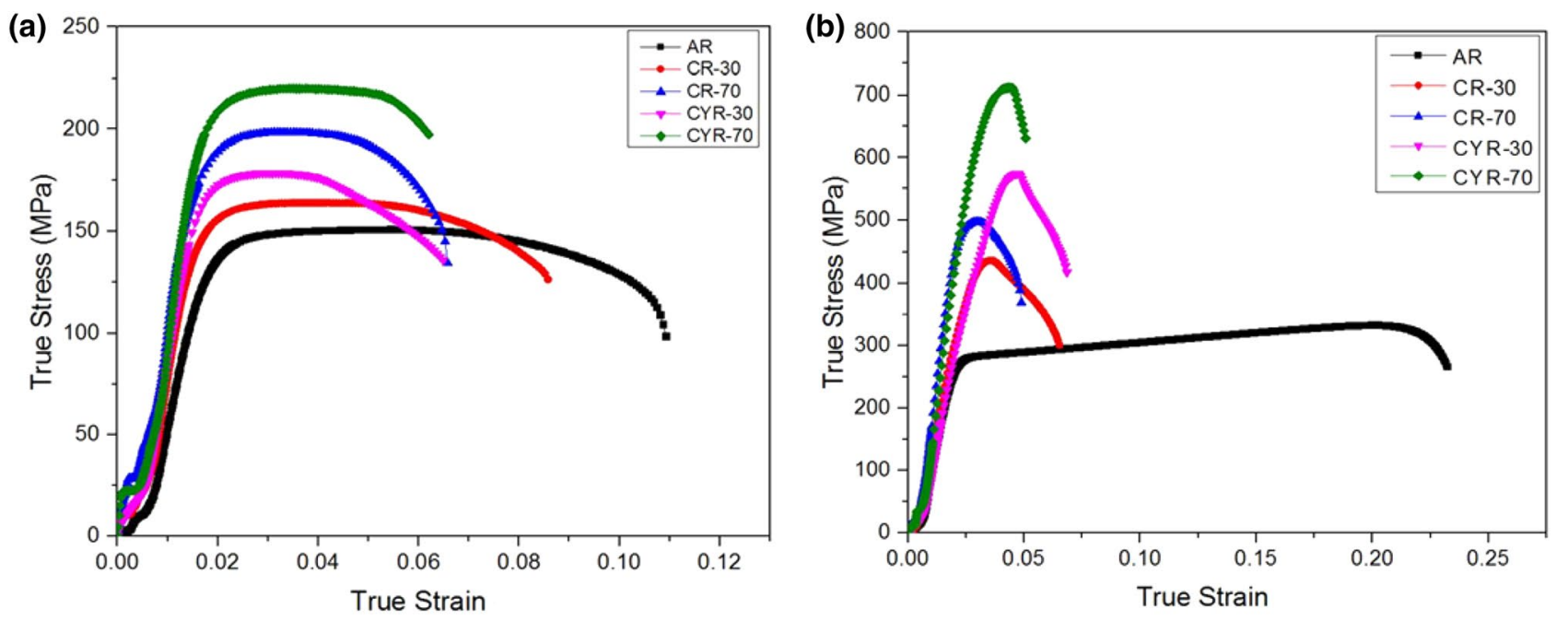

Fig. 3 True stress-strain diagram of cold and cryorolled sample with 30\% and 70\% thickness reduction a AA 3003 alloy and b pure Cu

Table 2 Tensile properties of initial and deformed AA-3003 and pure $\mathrm{Cu}$

\begin{tabular}{|c|c|c|c|c|c|c|}
\hline & \multicolumn{2}{|l|}{ YS (MPa) } & \multicolumn{2}{|c|}{ UTS (MPa) } & \multicolumn{2}{|c|}{ Elongation (\%) } \\
\hline & AA 3003 & Pure Cu & AA 3003 & Pure Cu & AA 3003 & Pure Cu \\
\hline AR & $124 \pm 2$ & $253 \pm 3$ & $126 \pm 3$ & $301 \pm 2$ & $12 \pm 2.2$ & $23.2 \pm 1.2$ \\
\hline CR 30 & $136 \pm 4$ & $332 \pm 2$ & $144 \pm 5$ & $423 \pm 4$ & $9.5 \pm 1.1$ & $6.8 \pm 3.3$ \\
\hline CR 70 & $168 \pm 6$ & $439 \pm 5$ & $192 \pm 2$ & $482 \pm 3$ & $7.9 \pm 2.4$ & $5.1 \pm 3.2$ \\
\hline CYR 30 & $160 \pm 8$ & $336 \pm 7$ & $163 \pm 4$ & $556 \pm 6$ & $7.1 \pm 2.2$ & $7.1 \pm 1.3$ \\
\hline CYR 70 & $190 \pm 10$ & $520 \pm 8$ & $213 \pm 5$ & $702 \pm 4$ & $6.0 \pm 3.2$ & $5.3 \pm 2.1$ \\
\hline
\end{tabular}

deformation [35]. Dynamic recovery is a common phenomenon that occurs during conventional rolling and acts as a thermal barrier to restrict the mobility of dislocations. It is difficult to produce ultrafine-grained microstructures in the samples through traditional thermo-mechanical process [36]. At extreme low temperatures, enthalpy and internal energy of atom decreases as it is a function of the temperature of the material. The kinetic energy of atom decreases lead to suppression of dynamic recovery, which increases the dislocation density. Increasing YS and UTS in cryorolled specimens are due to suppression of dynamic recovery during plastic deformation at cryogenic temperature resulting in increases the dislocation density. Since pure $\mathrm{Cu}$ is low stacking fault energy material, it has higher tendency to increase the YS and UTS compared to AA 3003 alloy (Table 2).

\subsection{X-ray diffraction analysis}

Figure 4 shows the XRD pattern of AA- 3 and $\mathrm{Cu}$ in CYR70 condition. It is clearly shown that $\mathrm{Cu}$ has higher peak broadening than AA-3 due to higher lattice strain and lower crystalline size. As explained earlier that low SFE material has higher ability to achieve UFG structured

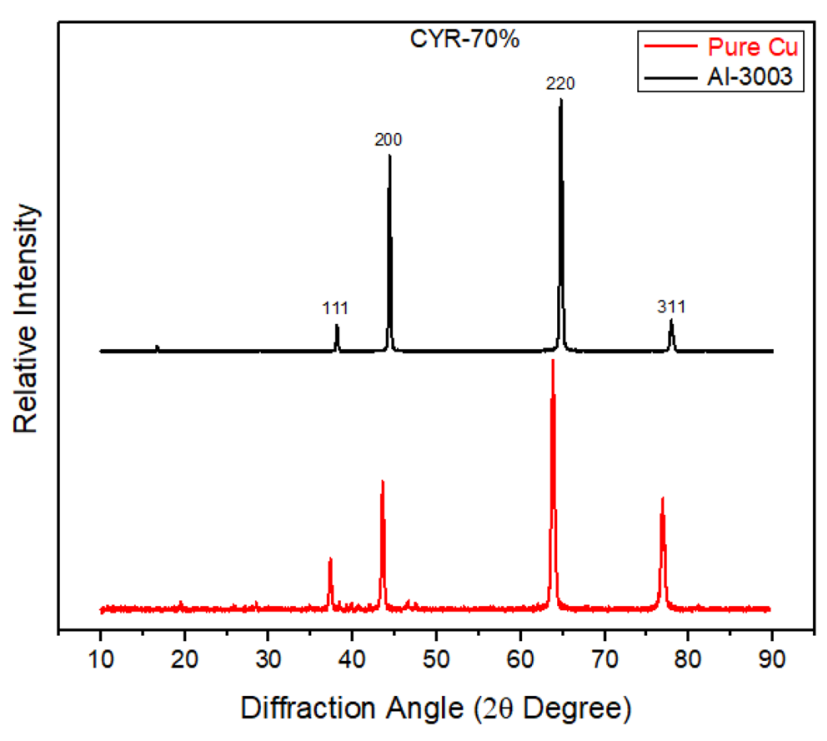

Fig. 4 X-ray analysis of AA 3003 and pure Cu for cryorolling with $70 \%$ reduction

than high SFE material due to significant amount of dislocations and twin density. The calculated results of crystallite size, lattice strain and dislocation density 
in CYR-70 condition for both the materials are listed in Table 3. The crystallite size observed in CYR Cu is $180 \mathrm{~nm}$, which is quite smaller than the crystallite size in CYR AA-3 while lattice strain and dislocation density are significantly higher in CYR Cu than in CYR AA-3. These results could be attributed to a high amount of deformation twins in Cu during cryorolling. Since (111) is a closepacked plane for FCC crystal structure, it is interesting to know the peak behavior in different FCC material for the same processing condition.

The typical enlarged view of (111) peak of both the materials in CYR-70 sample condition is illustrated in Fig. $5 \mathrm{a}$. The peak shift is observed in CYR Cu attributed to a high amount of lattice strain, internal stresses, and dislocation density. Figure $5 \mathrm{~b}$ shows the $\mathrm{W}-\mathrm{H}$ linear fitted plot of CYR-70 AA-3 and Cu. It has been shown that Cu has low scatter values for (111), (200), (220) and (311) planes than AA-3 which is also manifested by adjusted $R^{2}$ values from 0.86 for $A A-3$ to 0.97 for $\mathrm{Cu}$. The difference of this behavior indicates that the lattice strain becomes more homogeneous for $\mathrm{Cu}$ than AA-3 due to simultaneously accumulated the dislocation and twin density during cryorolling.

Table 3 Calculations of crystallite size, lattice strain and dislocation density from XRD plot

\begin{tabular}{lllll}
\hline Material & Condition & $\begin{array}{l}\text { Crystallite size } \\
(\mathrm{nm})\end{array}$ & $\begin{array}{l}\text { Lattice strain } \\
\left(\times 10^{-3}\right)\end{array}$ & $\begin{array}{l}\text { Dislocation } \\
\text { density } \\
\left(\times 10^{13} \mathrm{~m}^{-2}\right)\end{array}$ \\
\hline AA 3003 & CYR-70 & 361 & 1.0 & 1.62 \\
Pure Cu & CYR-70 & 180 & 2.0 & 6.52 \\
\hline
\end{tabular}

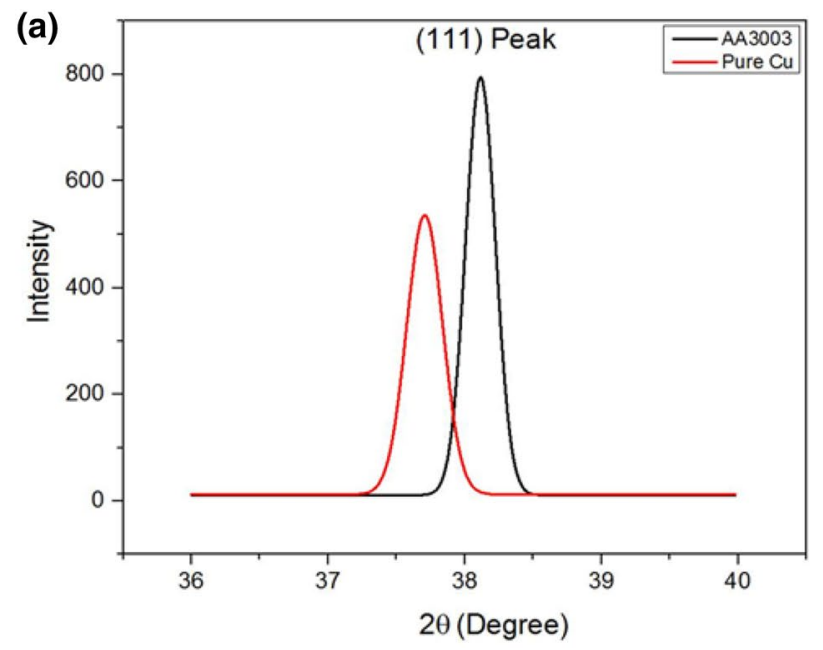

\subsection{Work hardening rate}

Work hardening explain gradually increases the strength of material up to one set of necking during uniform plastic deformation. The rate of work hardening of FCC materials is strongly dependent on an amount of strain applied and deformation temperature [37]. The work hardening rate is defined by the instantaneous change in true stress with respect to change in true strain. This phenomenon can be explained by potting the curve of work hardening rate with true strain, which is usually described as a Kocks-Mecking plot.

Figure $6 a-d$ shows the effect of work hardening rate with respect to true strain of AA-3 and $\mathrm{Cu}$ at different processing conditions. The work hardening behavior of CYR material is all time higher than CR material for each thickness reduction attributed to high dislocation density and grain refinement. Moreover, as shown in Fig. 6a-d, Cu has higher work hardening rate than AA-3 alloy, which signifies high densities of deformation twins, unlike the slip. The true stress (strain) value is also higher for $\mathrm{Cu}$ than AA-3 alloy. It is the fact that $\mathrm{Cu}$ (low SFE material) has higher tendency to get work hardening phenomena with optimized strength and ductility than AA-3 alloy (higher SFE material) and that is because of fine grain structure developed by the evolution of stress-induced grains in low SFE material. The different stages of work hardening are explained in details by various researchers [37-39]. Stage II hardening corresponds to the highest rate of strain hardening corresponding to dislocation multiplication and tangling. The interaction is generally independent of strain rate and temperature. Stage III is characterized by a linear decrease of strain hardening rate with increasing flow stress. Stage III is highly material dependent and the stress at which (b)

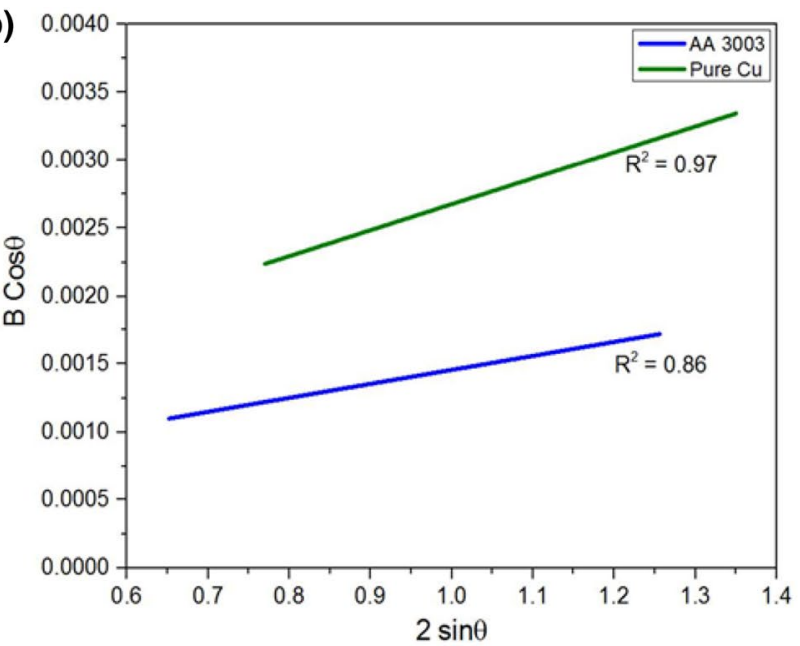

Fig. 5 a Enlarged view of XRD peaks and $\mathbf{b}$ Williamson-Hall linear fitted plot 

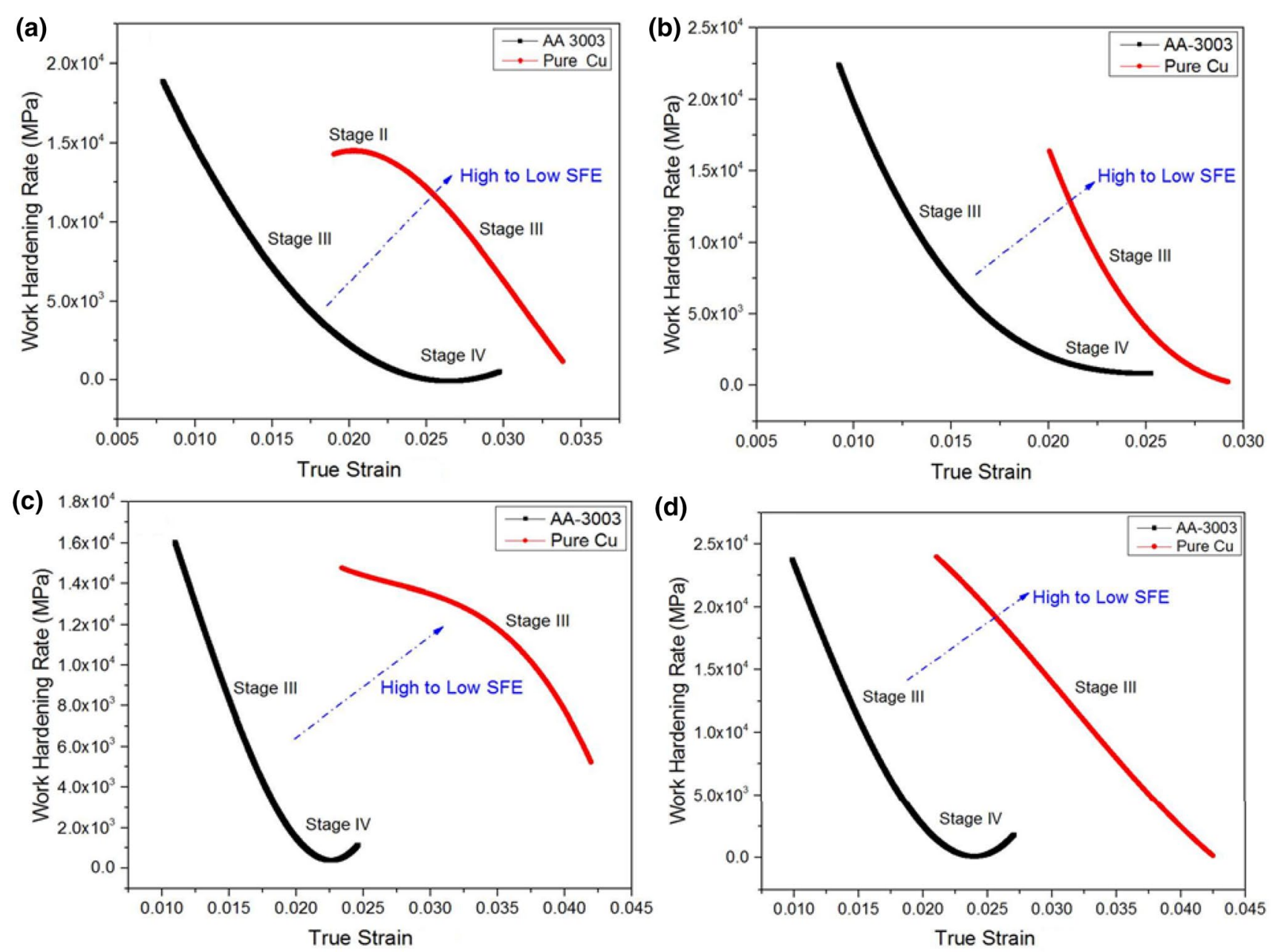

Fig. 6 Work hardening rate with respect to true strain for AA 3003 and pure Cu a CR-30, b CR-70, c CYR-30, and d CYR-70

this stage begins is very sensitive to temperature and rate of deformation. The hardening by dislocation accumulation and recovery by dislocation annihilation simultaneously occurs during this stage. It is to be noted that, stage IV hardening is gradually decreased from cold rolling to cryorolling. For $\mathrm{Cu}$, stage IV hardening is negligible for all processing conditions implies higher work hardening in Cu than in AA-3 alloy. Work hardening phenomena precisely correlated with the work hardening exponent ' $n$ ' of the material. Work hardening exponent ' $n$ ' can be calculated using the Hollomon power law equation. Material conditions with higher $\mathrm{n}$ values have better ductility and formability than those with lower $n$ values.

Figure 7 shows the variation of work hardening exponent with different rolling conditions and it indicates that CYR samples have lower $\mathrm{n}$ values than CR samples for each thickness reductions. It is clearly understood from true stress-strain curves that CYR samples have a steeper

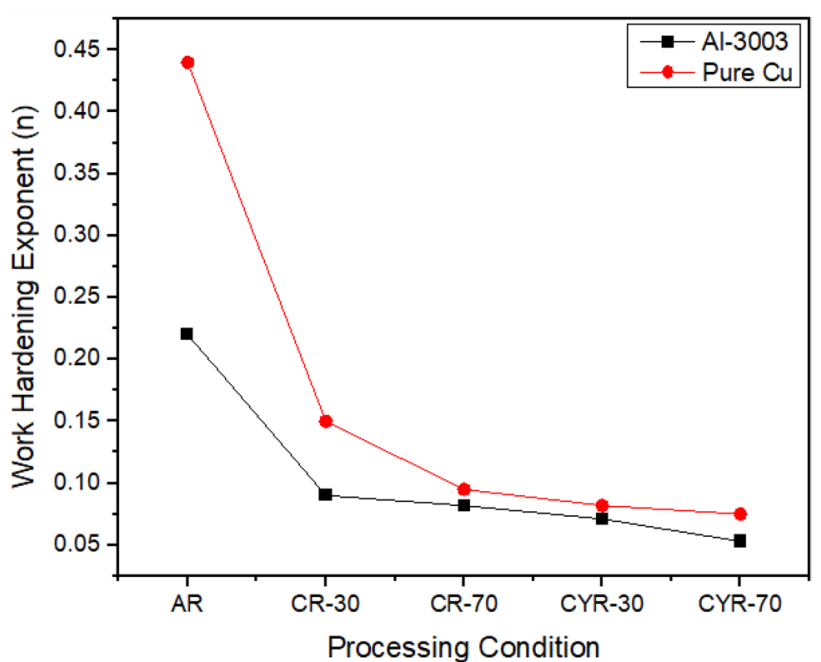

Fig. 7 Work hardening exponent (n) of AA 3003 and Pure Cu as a function of different processing condition 

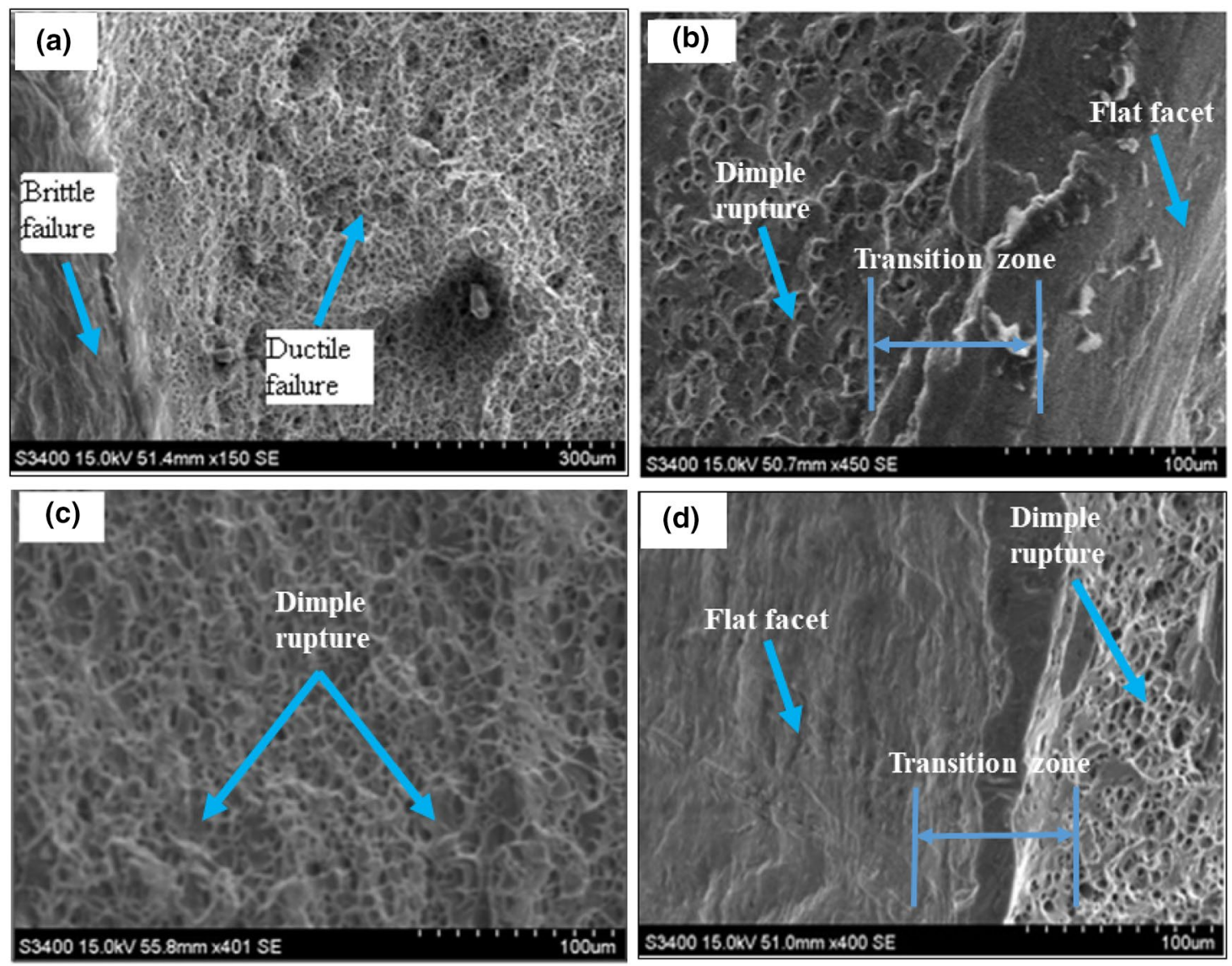

Fig. 8 SEM fractography of cold rolled and cryorolled AA 3003 alloy at different thickness reduction a CR-30, b CYR-30, c CR-70 and d CYR70

curve in uniform elongation than CR samples attributed to suppression of dynamic recovery at liquid nitrogen temperature. It should be noted that $\mathrm{Cu}$ has higher $\mathrm{n}$ values than AA-3 alloy for each thickness reduction and processing conditions. High $\mathrm{n}$ value in $\mathrm{Cu}$ is mainly due to lower SFE and twinning deformation mechanism in $\mathrm{Cu}$, which is consistent with the higher mechanical properties.

\subsection{Effect of stacking fault energy on mechanical properties}

Stacking fault energy (SFE) is one of the most imperative and intrinsic material parameters, which strongly affects on mechanical properties and microstructure of deformed materials. High SFE metals like AI $\left(160-200 \mathrm{~J} \mathrm{~m}^{-2}\right)$ is mainly deformed by slipping and low SFE metals like pure $\mathrm{Cu}$ and copper alloys $\left(70-78 \mathrm{~J} \mathrm{~m}^{-2}\right.$ ) are mainly deformed by twinning besides slip [40-42]. However, $\mathrm{Cu}$ and $\mathrm{Cu}$ alloys do not twin at the moderate strain level. Twinning occurs at low temperature with large plastic strain [43]. SFE is strongly dependent on deformation temperature and it decreases with temperature. It is also affect two different competitive deformation mechanisms such as twinning and slip. Slip is always a dominating mechanism in polycrystalline FCC materials at room temperature. However, deformation by twinning is more significant when the temperature is below $-170^{\circ} \mathrm{C}$ [44]. High SFE materials display narrow stacking fault, which has smaller dislocation core size, creates greater mobility for dislocations. Dislocations are easily separated into two Shockley partial dislocations with low SFE FCC materials. Cross slip is required to combine the separated partial dislocations. Low SFE materials display wider stacking fault ribbons and have more difficulties for cross-slip and climb of full dislocations. Therefore, the mobility of dislocation restricts and large stress is required for further plastic deformation. According to Rohatgi et al. [45], dynamic recovery of low SFE materials is delayed compared to high SFE materials. Due to that, high grain refinement achieved without losing ductility. 

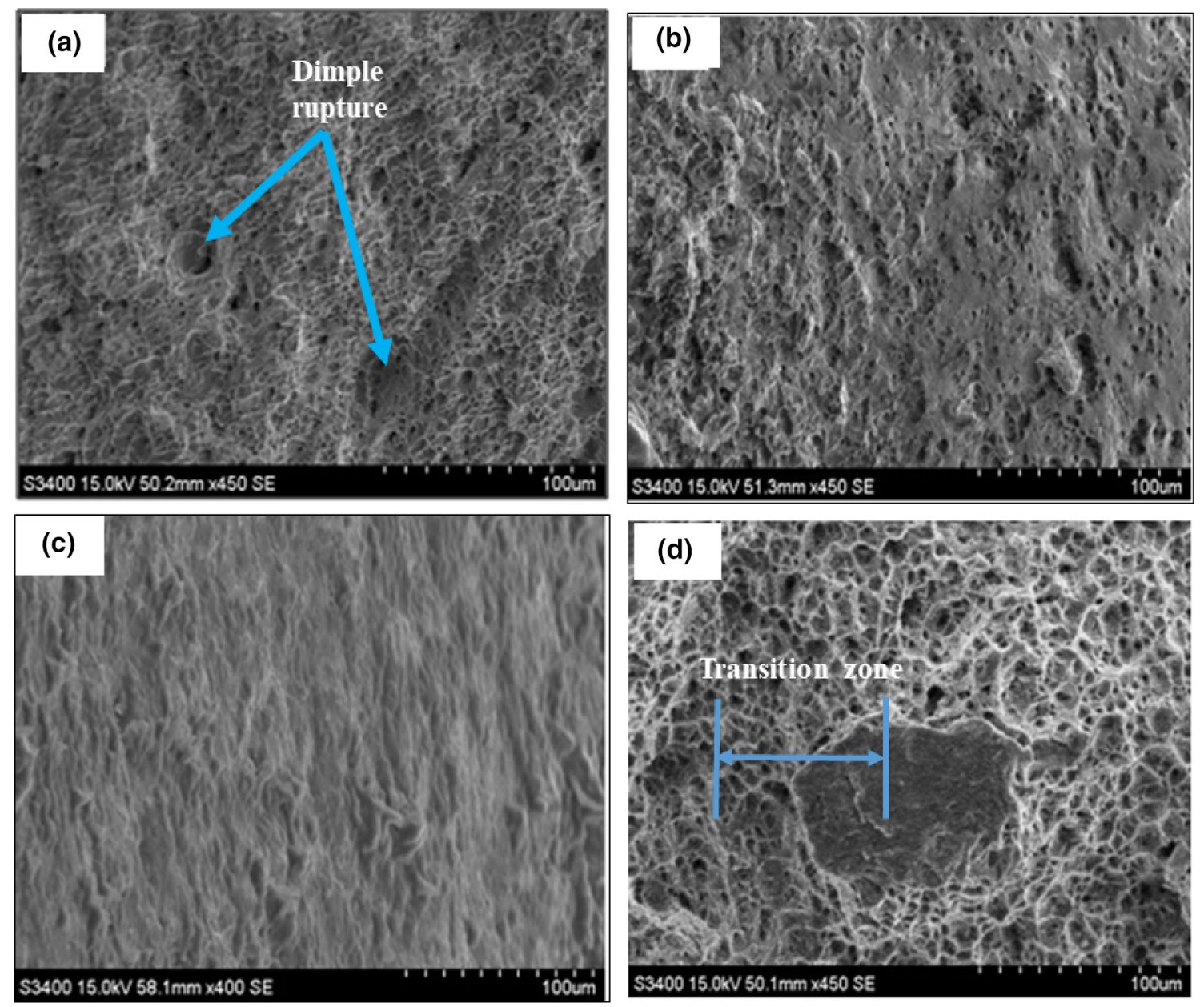

Fig. 9 SEM fractography of cold rolled and cryorolled pure Cu at different percentage of thickness reduction a CR-30, b CYR-30, c CR-70, d CYR-70

Simultaneous improvement of strength and ductility in cryorolled $\mathrm{Cu}$ and Cu based alloy is well-reported [44].

\subsection{Fractography analysis}

To understand the failure mechanism, fractography analysis of AA 3003 and pure Cu has been carried out on tensile fractured samples using SEM. The ductile failure are observed in the case of CR-30 and CR-70 sample conditions. A large number of dimples are shown in Figs. 8a, C, and $9 a$, c for CR-30 and CR-70, respectively while, the mixed mode of failure was observed in the case of CYR-30 and CYR-70 sample conditions as shown in Figs. 8b, $d$ and $9 b, d$, respectively. Void growth and void coalescence are responsible for dimples formation in the rolled samples. The number of dimples are decreased in the cryorolled samples and flat facet is also observed.
It is noted down that dimple size is gradually decreases with an increasing percentage of thickness reduction in cryorolled samples, which shows low ductility. The river marking of the flat facet is caused by the crack moving through the crystal along a number of parallel planes, which form a series of plateaus and shelves. This reveal the absorption of energy by local deformation.

The transition zone is clearly seen in cryorolled samples and failure mechanism transferred from flat facet to void growth signifies mix mode of failure. The similar results are found for pure $\mathrm{Cu}$ in the fractured tensile specimen. Jamaludin et al. [46] have also explained the similar behavior in Al-Mg-Si alloy. It is expected from the above observation that lower stacking fault energy materials give better grain refinement with relatively coarse grains results in delaying crack propagation. The mixed mode of failure with lower dimple size is observed in all cryorolled samples compared to cold rolled samples that indicate 
the severe strain hardening and grain refinement. Similar results are observed by Dasharath et al. [47]. The detailed analysis are required in the future to understand the effect of stacking fault energy on mechanical properties and fracture behavior of cryorolled and cold rolled materials.

\section{Conclusions}

Cryorolling can be a potential route to produce ultrafinegrained sheet metals compared to cold rolling. The mechanical properties and fractography of an AA 3003 alloy and pure $\mathrm{Cu}$ are evaluated under cold rolled and cryorolled conditions. The following conclusions are made based on the present study.

1. The hardness of the cryorolled AA 3003 alloy and pure $\mathrm{Cu}$ for $30-70 \%$ thickness reduction are increased by $5 \%$ and $8 \%$, respectively. The increasing of hardness revealed higher dislocation density and grain refinement on the CYR samples.

2. YS and UTS of cryorolled AA 3003 alloy and pure $\mathrm{Cu}$ are higher than cold rolled for $30 \%$ and $70 \%$ thickness reduction and it is due to the suppression of dynamic recovery at cryogenic temperature. However, the ductility has been reduced from the initial condition.

3. Being a low stacking fault energy material, pure Cu has higher tendency to increase the YS, UTS, and hardness compared to higher stacking fault energy material such as AA 3003 alloy. Dislocation movement by slip is restricting with low SFE and twinning mechanism is favoured for plastic deformation.

4. Work hardening rate of cryorolled samples are lower than cold rolled samples due to higher dislocation density and grain refinement. Pure $\mathrm{Cu}$ has higher ability to work hardened than AA 3003 alloy, which is attributed to lower stacking fault energy, and twinning mechanism.

5. Mixed mode (ductile and brittle) of failure was observed on cryorolled samples due to higher work hardening and grain refinement compared to cold rolled samples. Enough amount of dimples could be seen in pure Cu compared to AA 3003 alloy due to low staking fault energy in pure $\mathrm{Cu}$.

\section{Compliance with ethical standards}

Conflict of interest The authors declare that they have no competing interests.

\section{References}

1. Zhao Y (2011) Advanced mechanical properties and deformation mechanisms of bulk nanostructured materials. Volume 683 of materials science forum. Trans Tech Publications. Ltd, Switzerland

2. Hall EO (1951) The deformation and ageing of mild steel: III discussion of results. Proc Phys Soc Sect B 64:747-753. https://doi. org/10.1088/0370-1301/64/9/303

3. Petch (1953) The cleavage strength of polycrystals. I. Iron Steel Inst 174:24

4. Sabirov I, Enikeev NA, Murashkin MY, Valiev RZ (2015) Bulk nanostructured materials with multifunctional properties. Springer, New York

5. Zhu YT, Langdon TG (2004) The fundamentals of nanostructured materials processed by severe plastic deformation. JOM 56:58-63. https://doi.org/10.1007/s11837-004-0294-0

6. Gleiter H (1989) Nanocrystalline materials. Prog Mater Sci 33(4):223-315. https://doi.org/10.1016/0079-6425(89)90001-7

7. Koch CC, Cho YS (1992) Nanocrystals by high energy ball milling. Nanostruct Mater 1(3):207-212. https://doi.org/10.1016/09659773(92)90096-G

8. Kim BK, Lee GG, Ha GH, Lee DW (1999) Synthesis of nanostructured powders by new chemical processes. Met Mater 5(2):109113. https://doi.org/10.1007/BF03026039

9. Luton MJ, Jayanth CS, Disko MM, Matras S, Vallone J (1989) Cryomilling of nano-phase dispersion strengthened aluminum. Mater Res Soc Symp Proc 132:79. https://doi.org/10.1557/ PROC-132-79

10. Valiev RZ, Mulyukov RR, Ovchinnikov VV (1990) Direction of grain-boundary phase in submicometer-grained iron. Philos Mag Lett 62(4):253-256. https://doi.org/10.1080/0950083900 8215131

11. Valiev RZ, Krasiinikov NA, Tsenev NK (1991) Plastic deformation of alloys with submicron-grained structure. Mater Sci Eng, A 137:35-40. https://doi.org/10.1016/0921-5093(91)90316-F

12. Zehetbauer MJ, Zhu YT (2009) Bulk nanostrucutred materials. Wiley-Vch Verlag GmbH \& Co. KGaA, Weinheim

13. Valiev RZ, Langdon TG (2006) Principles of equal-channel angular pressing as a processing tool for grain refinement. Prog Mater Sci 51(7):881-981. https://doi.org/10.1016/j.pmats ci.2006.02.003

14. Edalati K, Horita Z (2016) A review on high-pressure torsion (HPT) from 1935 to 1988. Mater Sci Eng, A 652:325-352. https ://doi.org/10.1016/j.msea.2015.11.074

15. Toroghinejad MR, Ashrafizadeh F, Jamaati R (2013) On the use of accumulative roll bonding process to develop nanostructured aluminum alloy 5083. Mater Sci Eng, A 561:145-151. https://doi. org/10.1016/j.msea.2012.11.010

16. Panigrahi SK, Jayaganthan $R$ (2008) Effect of rolling temperature on microstructure and mechanical properties of $6063 \mathrm{Al}$ alloy. Mater Sci Eng, A 492(1-2):300-305. https://doi.org/10.1016/j. msea.2008.03.029

17. Changela K, Kumar S, Hariharan K, Kumar DR (2019) Aging behavior of ultra-fine grained AA 6061 alloy subjected to constrained groove pressing followed by cold rolling. IOP Conf Ser Mater Sci Eng 651:012069. https://doi.org/10.1088/1757899X/651/1/012069

18. Changela K, Krishnaswamy H, Digavalli RK (2019) Development of combined groove pressing and rolling to produce ultra-fine grained Al alloys and comparison with cryorolling. Mater Sci Eng, A 760:7-18. https://doi.org/10.1016/j.msea.2019.05.088

19. Changela K, Krishnaswamy H, Digavalli RK (2020) Mechanical behavior and deformation kinetics of aluminum alloys 
processed through cryorolling and subsequent annealing. Metall Mater Trans A 51:648-666. https://doi.org/10.1007/s1166 1-019-05532-2

20. Yogesha KK, Kumar N, Joshi A, Jayaganthan R, Nath SK (2016) A comparative study on tensile and fracture behavior of $\mathrm{Al}-\mathrm{Mg}$ alloy processed through cryorolling and cryo groove rolling. Metallogr Microstruct Anal 5:251-263. https://doi.org/10.1007/ s13632-016-0282-0

21. Wang Y, Chen M, Zhou F, Ma E (2002) High tensile ductility in a nanostructured metal. Nature 419:912-915. https://doi. org/10.1038/nature01133

22. Rangaraju N, Raghuram T, Krishna BV, Rao KP, Venugopal $P$ (2005) Effect of cryo-rolling and annealing on microstructure and properties of commercially pure aluminium. Mater Sci Eng, A 398(1-2):246-251. https://doi.org/10.1016/j.msea.2005.03.026

23. Lee TR, Chang CP, Kao PW (2005) The tensile behavior and deformation microstructure of cryo-rolled and annealed pure nickel. Mater Sci Eng, A 408(1-2):131-135. https://doi.org/10.1016/j. msea.2005.07.045

24. Singh D, Rao PN, Jayaganthan R (2013) Effect of deformation temperature on mechanical properties of ultrafine-grained AlMg alloys processed by rolling. Mater Des 50:646-655. https:// doi.org/10.1016/j.matdes.2013.02.068

25. Doherty RD, Hughes DA, Humphreys FJ, Jonas JJ, Jensen DJ, Kassner ME, King WE, McNelley TR, McQueen HJ, Rollett AD (1988) Current issues in recrystallization: a review. Mater Today 238(2):219-274. https://doi.org/10.1016/S0921-5093(97)00424 $-3$

26. Zhao YH, Zhu YT, Liao XZ, Horita Z, Langdon TG (2006) Tailoring stacking fault energy for high ductility and high strength in ultrafine grained Cu and its alloy. Appl Phys Lett 89:121906. https://doi.org/10.1063/1.2356310

27. Sun P, Zhao YH, Cooley JC, Kassner ME, Horita Z, Langdon TG, Lavernia EJ, Zhu YT (2009) Effect of stacking fault energy on strength and ductility of nanostructured alloys: an evaluation with minimum solution hardening. Mater Sci Eng, A 525(12):83-86. https://doi.org/10.1016/j.msea.2009.06.030

28. An XH, Lin QY, Wu SD, Zhang ZF, Figueiredo RB, Gao N, Langdon TG (2011) The influence of stacking fault energy on the mechanical properties of nanostructured $\mathrm{Cu}$ and $\mathrm{Cu}-\mathrm{Al}$ alloys processed by high-pressure torsion. Scr Mater 64(10):954-957. https://doi. org/10.1016/j.scriptamat.2011.01.041

29. Sarma VS, Wang J, Jian WW, Kauffmann A, Conrad H, Freudenberger J, Zhu YT (2010) Role of stacking fault energy in strengthening due to cryo-deformation of FCC metals. Mater Sci Eng, A 527(29-30):7624-7630. https://doi.org/10.1016/j. msea.2010.08.015

30. Tian YZ, Zhao LJ, Chen S, Terada D, Shibata A, Tsuji N (2014) Optimizing strength and ductility in $\mathrm{Cu}-\mathrm{Al}$ alloy with recrystallized nanostructures formed by simple cold rolling and annealing. J Mater Sci 49:6629-6639. https://doi.org/10.1007/s1085 3-014-8299-8

31. Satish DR, Feyissa F, Kumar DR (2017) Cryorolling and warm forming of AA6061 aluminum alloy sheets. Mater Manuf Process 32(12):1345-1352. https://doi.org/10.1080/10426 914.2017.1317352

32. Huang Y, Yan X, Qiu T (2016) Microstructure and mechanical properties of cryo-rolled AA6061 Al alloy. Trans Nonferrous Met Soc China 26(1):12-18. https://doi.org/10.1016/S1003 $-6326(16) 64083-9$

33. Williamson GK, Hall WH (1953) X-ray line broadening from filed aluminium and wolfram. Acta Metall 1:22-31
34. Feyissa F, Ravi Kumar D, Rao PN (2018) Characterization of microstructure, mechanical properties, and formability of cryorolled AA5083 alloy sheets. J Mater Eng Perform 27:1614-1627. https:// doi.org/10.1007/s11665-018-3243-8

35. Hull D, Bacon DJ (2011) Introduction to dislocations, 5th edn. Elsevier, Burlington. https://doi.org/10.1016/C2009-0-64358-0

36. Das P, Jayaganthan R, Singh IV (2011) Tensile and impacttoughness behaviour of cryorolled Al 7075 alloy. Mater Des 32(3):1298-1305. https://doi.org/10.1016/j.matdes.2010.09.026

37. Rollett AD, Kocks UF (1993) A review of the stages of work hardening. Solid State Phenom 35-36:1-18. https://doi.org/10.4028/ www.scientific.net/SSP.35-36.1

38. Poole WJ, Embury JD, Lloyd DJ (2011) Work hardening in aluminium alloys. In: Lumley R (ed) Fundaments of aluminium metallurgy-production, processing and application. Series in metals and surface engineering. Woodhead Publishing, Sawston

39. Kocks UF, Mecking $H$ (2003) Physics and phenomenology of strain hardening: the FCC case. Prog Mater Sci 48(3):171-273. https://doi.org/10.1016/S0079-6425(02)00003-8

40. Gong YL, Wen CE, Wu XX, Ren SY, Cheng LP, Zhu XK (2013) The influence of strain rate, deformation temperature and stacking fault energy on the mechanical properties of $\mathrm{Cu}$ alloys. Mater Sci Eng, A 583:199-204

41. Tian YZ, Zhao LJ, Chen S, Shibata A, Zhang ZF, Tsuji N (2015) Significant contribution of stacking faults to the strain hardening behavior of $\mathrm{Cu}-15 \% \mathrm{Al}$ alloy with different grain sizes. Sci Rep 5:16707. https://doi.org/10.1038/srep16707

42. Zhang XK, Yang XY, Chen W, Qin J, Fouse JP (2016) Effect of stacking fault energy on mechanical properties and annealing behavior of brasses. J Alloys Compd 679:400-407. https://doi. org/10.1016/j.jallcom.2016.04.083

43. Parmar V, Changela K, Srinivas B, Mani Sankar M, Mohanty S, Panigrahi SK, Hariharan K, Kalyanasundaram D (2019) Relationship between dislocation density and antibacterial activity of cryo-rolled and cold-rolled copper. Mater 12(2):200. https://doi. org/10.3390/ma12020200

44. Bahmanpour H, Kauffmann A, Khoshkhoo MS, Youssef KM, Mula S, Freudenberger J, Eckert J, Scattergood RO, Koch CC (2011) Effect of stacking fault energy on deformation behavior of cryorolled copper and copper alloys. Mater Sci Eng, A 529:230-236. https://doi.org/10.1016/j.msea.2011.09.022

45. Rohatgi A, Vecchio KS, Gray GT (2001) The influence of stacking fault energy on the mechanical behavior of $\mathrm{Cu}$ and $\mathrm{Cu}$-Al alloys: deformation twinning, work hardening, and dynamic recovery. Metall Mater Trans A 32:135-145. https://doi.org/10.1007/s1166 1-001-0109-7

46. Jamaludin SB, Abdullah MH, Mazlee MN, Hussin K (2015) Effect of solution treatment temperature on tensile strength of Al-Mg-Si alloy. Mater Sci Forum 819:39-44. https://doi. org/10.4028/www.scientific.net/MSF.819.39

47. Dasharath SM, Mula S (2016) Microstructural evolution and mechanical properties of low SFE Cu-Al alloys processed by cryorolling followed by short-annealing. Mater Des 99:552-564. https://doi.org/10.1016/j.matdes.2016.03.095

Publisher's Note Springer Nature remains neutral with regard to jurisdictional claims in published maps and institutional affiliations. 